Festival infantil? Festival infantil
de Teatro 3 
María Consuelo Martin Cardinal
1 Docente, Fundación Universitaria Monserrate. Maestría en Desarrollo Educativo y Social. CINDE-UPN.

\section{La Formación Docente en el trabajo con el cuerpo y el movimiento en Educación Inicial}

\section{Resumen}

El artículo propone unas reflexiones frente al lugar del cuerpo y el movimiento en la educación inicial, a partir de un ejercicio de sistematización de la práctica docente e investigativa; entendiendo al cuerpo y al movimiento como ejes centrales del trabajo pedagógico; busca presentar las características de la formación en este campo, que pasan por la vivencia, evocación y reflexión del propio ser corporal. Concluyendo que la formación y el ejercicio profesional requieren una mirada donde la seguridad y la escucha sean principios rectores de la acción educativa.

\section{Palabras clave: Formación} Docente, cuerpo, movimiento, vivencia personal, Educación Inicial.

\section{Teacher Education in working with the body and movement in Early Childhood Education}

\section{Summary}

This article offers some reflections opposite the place of the body and movement in early childhood education, from a systematic exercise of teaching and research practice, understanding the body and movement as central to the pedagogical work, seeks to present the characteristics of training in this field, who go through the experience, evocation and body self reflection. Concluding that training and practice require a look where security and listening are guiding principles of educational action.

Keywords: Teacher training, body, movement, personal experience, Early Childhood Education.

\section{A Formação Docente no trabalho com o corpo e o movimento em Educação Inicial}

\section{Resumo}

0 artigo propõe umas reflexões em frente ao lugar do corpo e o movimento na educação inicial, a partir de um exercício de sistematização da prática docente e investigativa; entendendo ao corpo e ao movimento como eixos centrais do trabalho pedagógico; procura apresentar as características da formação neste campo, que passam pela vivência, evocación e reflexão do próprio ser corporal. Concluindo que a formação e o exercício profissional requerem uma mirada onde a segurança e a escuta sejam princípios reitores da acção educativa.

Palavras-chave: Formação Docente, corpo, movimento, vivência pessoal, Educação Inicial. 


\section{Introducción}

$\mathrm{E}$ ste artículo es fruto del trabajo de sistematización de la práctica docente e investigativa de la autora, entre los años 2000-20112; fue apoyada por el programa de Educación Preescolar de la Fundación Universitaria Monserrate. El trabajo tuvo como propósito central sistematizar la práctica docente e investigativa en el campo de la lúdica y la psicomotricidad, para la experiencia concreta del caso estudiado, con el fin de realizar un aporte a la educación inicial y a la formación docente que se ocupa de estas temáticas. Para los fines del presente escrito se recogen especialmente los hallazgos encontrados en el campo de la psicomotricidad; el desarrollo de la sistematización giró alrededor de las fases que se presentan a continuación.

\section{Fase 1. Recopilación de la información}

En esta etapa se recopiló la información relativa a: los programas de las asignaturas referentes al campo de Lúdica y Psicomotricidad; los proyectos pedagógicos desarrollados por las estudiantes en los centros de práctica; los proyectos de investigación de docentes y estudiantes y, finalmente, los informes de la comunidad académica correspondientes al período 2000-2011. Así mismo, se realizaron dos conversatorios con estudiantes y con egresadas del programa de Licenciatura en Educación Preescolar.

\section{Fase 2. Organización de la información}

Una vez recopilada la información, se procedió a ordenarla según las fuentes consultadas y teniendo en cuenta los siguientes ejes: qué (contenidos, enfoque), para qué (intencionalidades), por qué (justificación), y cómo (metodologías, formas de trabajo). Para organizar adecuadamente los datos obtenidos,

2 Proyecto: Sistematización de la Práctica Docente e Investigativa en el campo de la lúdica y la psicomotricidad en el Programa de Licenciatura en Educación Preescolar de la Fundación Universitaria Monserrate.2012 Investigadora principal: María Consuelo Martín- Estudiantes Auxiliares de Investigación: Adriana Lizeth Lugo, Diana Milena Andrade. se diseñaron unas matrices según cada fuente de información: programas académicos, proyectos pedagógicos, proyectos de investigación y comunidad académica.

\section{Fase 3. Descripción, análisis e interpretación de la información}

Para esta fase se diseñó un cuadro en el que se evidencia el año, período, eje, rasgos y categorías por tipo de fuente. El procedimiento que se siguió para el análisis y la interpretación consistió en:

1. Agrupación de la información por ejes.

2. Establecimiento de rasgos para cada eje.

3. Lectura global de los rasgos, determinación de similitudes y diferencias.

4. Conformación de las categorías, nominación y definición.

5. Elaboración de un texto descriptivo-interpretativo por eje.

\section{Resultados}

\section{- El lugar del cuerpo y el movimiento}

A partir de algunas de las categorías que surgieron del proceso analítico desarrollado, fue posible determinar, entre otros aspectos, el lugar del cuerpo y movimiento en la práctica docente en el nivel inicial. Para estudiar esta presencia, se hizo necesario hacer un análisis de los espacios, tiempos, documentos institucionales y observaciones de las prácticas en el aula.

Estos elementos permitieron determinar cuáles son los espacios físicos disponibles en las instituciones para la exploración y descubrimiento de las capacidades corporales, en qué tiempos hacen presencia el cuerpo y el movimiento y cuál es el carácter de esta presencia; en cuanto a los documentos institucionales, el estudio permitió reconocer cómo se registran los contenidos e intencionalidades respecto a la Educación del cuerpo y por el cuerpo. Fue necesario complementar el estudio con la observación directa de las prácticas docentes, pues es mediante este ejercicio que realmente se constata cuál es la concepción que permea la intervención pedagógica. 


\section{Hay espacios-tiempos donde los niños y niñas logran hacer de su cuerpo un medio de expresión, comunicación y creación"}

Se encontró entonces que en algunas instituciones, la presencia del cuerpo de los niños y niñas se limita principalmente a una configuración que la entiende como un instrumento para la construcción eficaz de los aprendizajes, y el trabajo que la involucra se centra especialmente en tres aspectos: el manejo de posturas, primordialmente, en la realización de actividades gráficas; el afianzamiento de la motricidad fina, por medio de la elaboración de guías, y la realización de movimientos orientados por el docente para centrar o disponer a los niños y las niñas para la clase.

Lo anterior hizo evidente que la presencia del cuerpo está mediada por el ajuste, el control y la imitación. No obstante, hay espacios-tiempos donde los niños y niñas logran hacer de su cuerpo un medio de expresión, comunicación y creación. Estos momentos ocurren especialmente en los descansos o cuando el adulto no está presente, pero también gracias a la acción pedagógica intencionada de un docente en situaciones como las propuestas en clase de expresión corporal o los momentos de bienvenida y despedida.

Así, indagando un poco más, se observa que en ocasiones el cuerpo en todas sus posibilidades no hace presencia, por un temor a perder el control de las situaciones o por la necesidad de generar un producto concreto que dé cuenta del trabajo realizado; de ahí el uso de actividades manua- les y decorados que remiten a la habilidad motriz lograda por los niños y las niñas.

Se plantea, entonces, la experiencia vital con el cuerpo, como algo que va más allá del desarrollo de la motricidad fina, dándole un lugar a todas sus manifestaciones; así, se proponen actividades donde el cuerpo se mueve, se expresa, conoce e interactúa con el medio desde una dinámica afectiva y globalizadora, logrando el fortalecimiento del desarrollo social, emocional y comunicativo, especialmente la construcción de la propia identidad y el reconocimiento de los otros.

Todo ello, por medio de experiencias corporales de encuentro consigo mismo y con los otros; el desarrollo de la seguridad y confianza a través de actividades de expresión motriz y la capacidad de crear y descubrir lo que su cuerpo puede hacer en la interacción con los objetos y el espacio. Como lo define Aucouturier (2004): "la expresividad motriz es la manera que cada niño tiene de manifestar el placer de ser él mismo, de construirse de una manera autónoma y de manifestar el placer de descubrir y de conocer el mundo que lo rodea" (p. 130). Siempre, partiendo de la base de que un niño que se ha apropiado de su cuerpo, tiene conciencia del mismo, y se ha movido y descubierto sus posibilidades, seguramente logrará ajustar sus posturas, movimientos y acciones a los requerimientos del entorno.
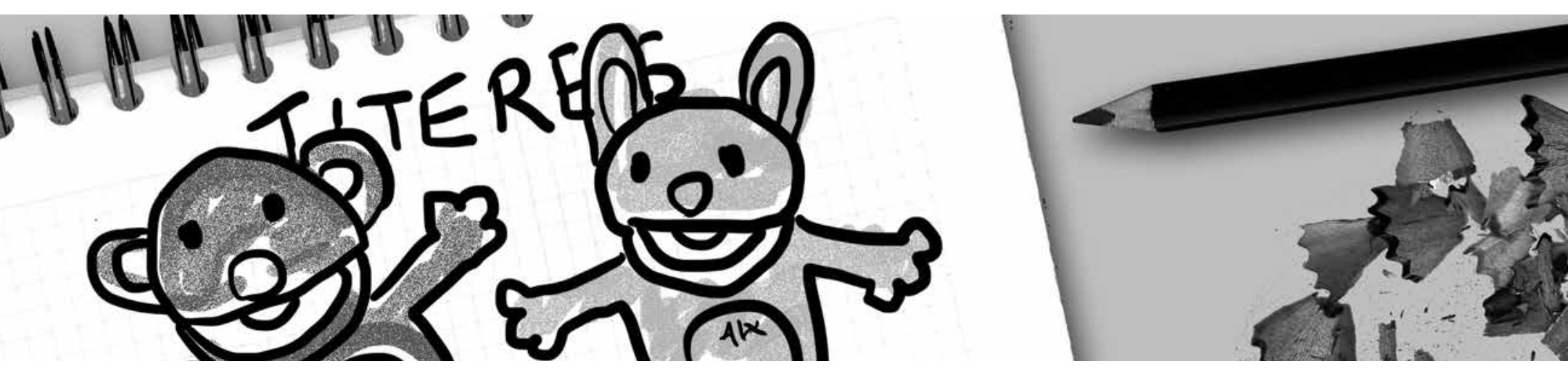

76 Educación y Ciudad No24 Enero - Junio de 2013 ISSN 0123-0425 pp. 73-79 


\section{Si el estudiante vive estas experiencias de carácter abierto, va asumiendo el respeto a la diversidad de ritmos y estilos, lo que le acerca a un proceso pedagógico más flexible y ajustado a las características propias"}

\section{- La formación del docente}

En el trabajo realizado, se resalta la importancia de tener una formación y una práctica docente, orientadas por unos principios que permitan comprender cómo el cuerpo y el movimiento se pueden convertir en el eje transversal del trabajo pedagógico con primera infancia; entendiendo que el trabajo pedagógico con el cuerpo y el movimiento no se limita al desarrollo de las destrezas motrices, seguir instrucciones, o a servir a la adquisición de hábitos, normas y procesos de atención, sino que va más allá, sujetando la construcción de la identidad y el desarrollo comunicativo y social.

En este sentido, el abordaje pedagógico de esta dimensión, se concibe desde su componente relacional y por lo tanto implica un proceso formativo mediado por la implicación personal y la toma de conciencia de su ser corporal: "los conceptos de respeto, acogida, escucha, comprensión serían sólo palabras sino se han vivido, experimentado, interiorizado" (Aucouturier, 2004, p. 202).

¿Cuál sería, entonces, la especificidad de la formación de los docentes que van a trabajar con los niños y niñas de primera infancia, desde el campo del cuerpo y el movimiento?

Comprendiendo que el docente en este ciclo vital, tiene un rol marcado por la acogida, la creación de vínculos, la contención y la escucha de los mensajes que a nivel no verbal emiten los niños; es importante contar con espacios formativos, que les permitan a los estudiantes el encuentro consigo mismos desde su ser corporal y lúdico.

Los futuros docentes requieren de una preparación que pase por su cuerpo, que los toque en todo el sentido de la palabra, que pueda hacer conscientes sus formas de comunicación, sus posibilidades expresivas, creativas y lúdicas. Esto se logra, según Arnaiz (2001), con: "Una formación que moviliza el espíritu, las actitudes y las emociones de las personas y las sumerge en un camino de autoformación" (p.90). Integrando la formación personal, teórica y práctica.

Así, la formación pasa por la evocación de las experiencias significativas vividas en la infancia con el movimiento, los espacios y objetos; es en esta medida que los futuros docentes se sensibilizan y comprenden la importancia del cuerpo en la infancia. Los talleres les posibilitan encontrar y revivir el placer sensorio-motor; cuando un estudiante experimenta lo que hacía en su infancia, la diversión, el gusto y la emoción compartida de la experiencia vivida, se le permite una conexión con su infancia de hoy y la posibilidad de asumir la acción psicomotriz desde una perspectiva integral, en la que su implicación emocional, cognitiva y motriz es indisociable.

Igualmente, si el estudiante vive estas experiencias de carácter abierto, va asumiendo el respeto a la diversidad de ritmos y estilos, lo que le acerca a un proceso pedagógico más flexible y ajustado a las características propias de cada niño y niña. En este ejercicio, cobran también gran valor los momentos de comunicación tónica, en los que se pone a prueba su capacidad de diálogo y escucha de los mensajes del otro por medio del contacto cuerpo a cuerpo, directo o mediado por un objeto; en la vivencia de lo que Ajuriaguerra (1975), llamó el "diálogo tónico", elemento esencial en la relación con los niños y las niñas pequeños.

De otra parte, en ese proceso formativo, el manejo de recursos no estructurados (telas, cojines, tubos de cartón, etc.), crea las condiciones para descubrir usos no convencionales de los mismos y percibir de una manera innovadora su carácter pedagógico, para el diseño de experiencias y ambientes con los niños y las niñas.

Uno de los elementos que se resaltan en este recorrido, es la capacidad de observar y hacer un seguimiento de los procesos de niños y las niñas, al tiempo que de la intervención 
del docente. Se propone entonces un instrumento que contenga aspectos como:

- Contenidos trabajados: componentes de la psicomotricidad como el tono, la coordinación, el equilibrio.

- Secuencias: entendidas como los momentos de la actividad, su ordenamiento y articulación.

- Materiales: tipo, uso.

- Espacio: organización, apropiación, ubicación.

- Agrupamientos: disposición en grupo, parejas o individual.

- Implicación en el trabajo: nivel de participación en la actividad, iniciativa, actitud, ánimo.

- Intervención del docente: actitud, disponibilidad, participación.

Así, se diseñan una variedad de ejercicios de observación y registro que acercan al futuro docente a caracterizar el movimiento de los niños y las niñas, su significado (por qué se mueven, cómo se mueven, para qué se mueven) y determinar las acciones pedagógicas más acordes, y también hacer una mirada a su propia intervención, reflexionando frente a su capacidad de escucha, empatía y sus posibilidades de contención y acompañamiento al proceso que viven los niños y las niñas.

De esta manera, es importante presentar actividades en las que se organicen y diseñen espacios para el desarrollo de la psicomotricidad, entendiendo el diseño de ambientes como la estructuración de espacios físicos, la disposición de determinados objetos y el establecimiento de un rol particular por parte del adulto, que contempla la observación del comportamiento psicomotor a partir de unas herramientas específicas. En este marco, la propuesta formativa en el campo del cuerpo y el movimiento para los futuros docentes, incluye aspectos de orden teórico que fundamentan su hacer pedagógico y la reflexión de sus prácticas y sus vivencias, que contribuyen a construir un saber experencial (Tardiff, 2009) en este campo.

\section{Conclusiones}

Dentro de las reflexiones que suscita este ejercicio analítico-descriptivo, y en el contexto de un proceso formativo que concibe al individuo en su integralidad, es posible destacar las siguientes conclusiones:
- Es importante profundizar en la red de relaciones tejidas entre los diferentes componentes que entran en juego para una sesión de clase en la que el cuerpo y el movimiento están presentes de manera intencional, con el objetivo de modificar las estrategias metodológicas de acuerdo con las características del comportamiento psicomotor de los niños; al tiempo, hay que favorecer la toma de conciencia sobre el propio cuerpo y las posibilidades que éste brinda para expresar e interactuar; además, hará falta una utilización del cuerpo que no sólo lo considere como instrumento de aprendizaje, sino como fundamento de proyección personal y social y, por último, buscar la vivencia del diálogo corporal y situaciones afectivas con los demás.

- Existen una serie de principios que orientan el quehacer del docente en una propuesta donde los ejes centrales son el cuerpo y el movimiento; por ejemplo: el docente debe disponer, observar y seguir el proceso, asumir una actitud no directiva, fomentar la autoreflexión, la toma de conciencia, el autoconocimiento y emplear un lenguaje de valoración y aceptación frente a todas las producciones.

Así mismo, se requiere de una permanente disponibilidad para la escucha de los mensajes no verbales que emite el niño $\mathrm{y}$ un potenciamiento de sus capacidades en este campo, por medio de experiencias enriquecidas. En palabras de Aucouturier (2004): "Un marco asegurador constituido por un espacio $\mathrm{y}$ un material que se pone a disposición del niño y mantenido por la disponibilidad de la acogida y por la escucha emocional del psicomotricista, el niño se sentirá arropado y capaz de vivir sin reservas su expresividad motriz cargada de intensamente de afecto de placer" (p. 132).

- Uno de los aportes más significativos que brinda el trabajo pedagógico con el cuerpo y el movimiento, para el desarrollo integral y la educación de los niños y las niñas, es la vivencia corporal como la posibilidad de construirse y reconocerse como ser único, autónomo y auténtico.

- Para asumir la presencia plena del cuerpo y el movimiento en las instituciones de educación inicial, y volver esa presencia patente en las prácticas docentes, es necesario detenerse a analizar los tiempos, espacios, lineamientos, la practica en el aula y, fundamentalmente, el rol del docente y su implicación en este tipo de trabajo. 


\section{Referencias}

Ajuriaguerra. (1975). Manual de psiquiatría infantil. Barcelona: Toray-Masson

Arnaiz, P., Radaban, M., y Vives, I. (2001). La psicomotricidad en la escuela: Una práctica educativa y preventiva . Málaga: Aljibe.
Aucouturier, B. (2004). Los fantasmas de acción y la práctica psicomotriz. Barcelona: Graó.

Tardif, M. (2009). Los saberes del docente y su desarrollo profesional. Madrid: Editorial Narcea. 


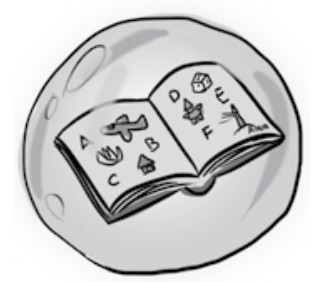

